\title{
Autonomía médica y ley estatutaria de salud
}

\author{
Medical autonomy and statutory health law
}

\author{
Jaime Calderón • Bucaramanga (Colombia)
}

La sociedad colombiana en los últimos 23 años ha hecho tránsito desde la prestación de un servicio de salud, financiado por el Estado y complementado con aseguramiento para la población trabajadora y sus beneficiarios, hacia un modelo de aseguramiento universal con subsidio a la demanda, y con un plan de beneficios único con exclusiones explícitas, reconociendo de manera plena la autonomía con autorregulación de los profesionales de la salud, y dentro del marco de la validación constitucional de la salud como un "derecho fundamental autónomo e irrenunciable en lo individual y en lo colectivo".

Este viaje social no ha estado libre de logros y fracasos. Los principales logros han sido el crecimiento en la equidad en la prestación de los servicios, y la mayor conciencia del ciudadano del derecho que le asiste.

El principal fracaso ha consistido en la mercantilización del sistema que conlleva mecanismos de transacción tramposos, y que condujeron a la pérdida de la autonomía profesional y por ende a múltiples afectaciones a la prestación de los servicios de salud a los enfermos y a los sanos, generando eso sí, grandes rentabilidades para aseguradores, prestadores y funcionarios, con el corolario de un inmenso desperdicio de enormes, pero aún insuficientes recursos del sistema.

La Ley Estatutaria de Salud, recientemente sancionada por el presidente Santos, es a la vez un punto final y un punto de partida. Ningún agente ni usuario del sistema permanecerá con las mismas condiciones que tenía previas a la expedición de la ley que entró a regir a partir del pasado febrero 16, y que deroga a partir de esa fecha, todas las leyes y disposiciones que le sean contrarias, incluyendo las contenidas en la Ley 100 de 1993 , en la 1122 y en la 1438.

Por ser ley estatutaria, es una prolongación de la Constitución, con el objetivo de garantizar el derecho fundamental a la salud, regularlo y establecer sus mecanismos de protección, responsabilizando al Estado del respeto, la protección y la garantía del derecho, teniendo en cuenta varios elementos y principios, entre ellos el de la progresividad, la libre elección, la adopción e interpretación más favorable de la norma y por supuesto la sostenibilidad.

En cuanto a esta última, La Corte Constitucional sentenció que: “...la sostenibilidad fiscal encuentra arraigo constitucional...no tiene el estatus de principio, sino de criterio orientador e instrumento al servicio de los objetivos del Estado social de derecho... y ninguna autoridad, puede prevalerse de tal herramienta para restringir el alcance o negar la protección efectiva de los derechos fundamentales".

Dicho lo anterior, supera el alcance de este artículo hacer un análisis minucioso de la sentencia de la Corte Constitucional que la declaró exequible, y por lo tanto me concentraré en hacer los comentarios pertinentes al artículo 17 del capítulo III de la ley estatutaria 1751 de 2015, por considerarlo la piedra angular del cambio del sistema y mediante el cual : "Se garantiza la autonomía de los profesionales de la salud para adoptar decisiones sobre el diagnóstico y tratamiento de los pacientes que tienen a su cargo. Esta autonomía será ejercida en el marco de esquemas de autorregulación, la ética, la racionalidad y la evidencia científica. Se prohíbe todo constreñimiento, presión o restricción del ejercicio profesional que atente contra la autonomía de los profesionales de la salud, así como cualquier abuso en el ejercicio profesional que atente contra la seguridad del paciente. La vulneración de esta disposición será
Dr. Jaime Calderón Herrera: Presidente Asociación Colombiana de Sociedades Científicas. Bucaramanga (Colombia).

Correspondencia: Dr. Jaime Calderón. Bucaramanga (Colombia).

E-mail: jaimecalde@yahoo.com

Recibido: 15/III/2015 Aceptado: 16/III/2015 
sancionada por los tribunales u organismos profesionales competentes y por los organismos de inspección, vigilancia y control en el ámbito de sus competencias".

Para la Corte Constitucional, el ejercicio médico se encuentra "estructurado a partir de dos principios fundamentales: capacidad técnica del médico y consentimiento idóneo del paciente". Además, "la autonomía es una expresión indispensable de la libertad... de tal modo, que al pretender correlacionar los deberes y derechos de los médicos frente a pacientes, la autonomía y su regulación, son criterios forzosos para delimitar recíprocamente los ámbitos de actuación de unos y otros...el considerar a la persona autónoma tiene sus consecuencias inevitables e inexorables, y la primera y más importante de todas consiste en que los asuntos que sólo a la persona atañen, sólo por ella deben ser decididos. Decidir por ella es arrebatarle brutalmente su ética, reducirla a la condición de objeto, cosificarla, convertirla en medio para los fines que por fuera de ella se eligen".

La ley sancionada convierte en un mandato para la nación, la autonomía médica dentro de un marco de autorregulación.

Y no podría ser de otra manera, en tanto que el privilegio que concede la sociedad a esta profesión, tiene que ver con el ejercicio profesional, con la práctica médica mediada por los principios de no hacer daño, ofrecer lo más efectivo y más seguro para el enfermo, respetando a la vez la autonomía del mismo, dentro de un marco de altruismo y calidad, y siempre con un criterio de justicia que involucra el uso equitativo y racional de los recursos puestos a su disposición y definidos por la ley como de carácter público con las implicaciones legales que ello acarrea.

Es una gran noticia en momentos que médicos y enfermos reclamamos la normalización de lo que se ha conocido como la relación médico-paciente, en mala hora destruida por la implementación de un sistema de medicina gerencia$d a$, más preocupado por la contención de gastos en salud que por el bienestar de los ciudadanos. La medicina gerenciada ha privilegiado los costos sobre la calidad.

En alguna ocasión vi un aviso clasificado de alguien, quien buscaba ser atendido por un médico que cumpliera dos condiciones: la primera, que no tuviera computador, la segunda, que estuviera dispuesto a mirarle a los ojos.

Pudiera decirse que es una exageración de la práctica médica actual, pero creo más bien que no refleja toda la deshumanización que se vive en el día a día, pues los enfermos no sólo deben desbrozar una maraña de obstáculos físicos, administrativos, económicos y médicos para obtener una atención, sino que además, cuando logran acceder a ella, pasan de mano en mano entre personal administrativo, auxiliares médicos, estudiantes, profesionales de diversa especialidad, que desmiembran su organismo, sin lograr que un ser humano capacitado y altruista lo mire como un todo, integre sus diferentes patologías y lo trate como una persona.

Desde el otro lado de la relación, los médicos nos sentimos constreñidos, irrespetados, ofendidos y sometidos a un régimen que obstaculiza la realización profesional, que pone trabas a la capacitación y a la actualización independiente. Que no decir de las trampas a la realización personal, que impiden a muchos de los médicos persistir en un entorno familiar saludable, en una condición laboral estable y dignamente remunerada. Después de invertir una fortuna en su capacitación, un médico general tarda diez años, y un especialista diez y seis años en recuperar el costo invertido en su formación, sometido a jornadas extenuantes, con retraso en los pagos, con intermediaciones onerosas y con agendas informales que lo asemejan a los siervos de la era feudal. Sólo una minoría de médicos empresarios logra éxitos económicos, pero no llegan a representar al $1 \%$ de los médicos colombianos.

Una sociedad, un Estado, un sistema que no cuida a sus cuidadores, nunca podrá tener una atención humanizada y de calidad.

A finales de los años ochenta del siglo pasado, los economistas vieron como una oportunidad para combatir la recesión y mejorar el crecimiento económico, insertar en la economía real, el gasto en educación y en salud. Para esto debieron transformar estos dos servicios en mercancías objetos de transacción y de lucro. Lo lograron, y los efectos económicos esperados se dieron.

Los esfuerzos se concentraron en ampliar estos mercados mediante la meta de cobertura universal, Para obtenerlo, la calidad y la humanización fueron sacrificadas.

En salud, fueron desempolvados los estudios probabilísticos como la forma de generar una evidencia de carácter científico, para sustentar una supuesta práctica médica adecuada, en medio de las incertidumbres y particularidades de los enfermos, que son el pan diario del ejercicio de la medicina. No hay enfermedades sino enfermos, se conoce desde la antigüedad, y tal concepto sigue vigente.

Implementada la Medicina Basada en la Evidencia (MBE), con el propósito de hacer "recomendaciones explícitas para situaciones específicas, fundamentadas en investigación validada estadísticamente", ésta se convirtió en la base para generar guías de práctica, que mal usadas por auditores y funcionarios administrativos, y aun por médicos desinformados, convirtieron la MBE en el instrumento para constreñir el acto médico, desconociendo que las situaciones estándar son la excepción en medicina y que la opinión de expertos, es también evidencia que cobra valor en la mayoría de las situaciones particulares de los enfermos, que no encajan en la evidencia generada con pacientes sometidos a criterios de inclusión y de exclusión, que muchas veces no reflejan el universo de los mismos.

Por supuesto que la autonomía médica requiere de la autorregulación, y para ello es necesario encajar la práctica profesional en unos estándares basados en la mejor evidencia disponible, los cuales deben ser adoptados libremente por los profesionales, sin constreñimiento, pero sí, con adherencia formal, para lo cual se impone que el modelo 
de atención esté fundamentado en servicios formales, con jerarquización, con práctica académica, con condiciones laborales y remunerativas que permitan a los médicos aspirar a un propósito de vida con realizaciones personales, académicas, laborales y familiares.

Pero no bastan los estándares con o sin los criterios de la MBE. La autonomía medica con autorregulación exige la transparencia y la visibilidad de los conflictos de interés, de tal manera que nada se anteponga a los intereses de los enfermos. De hecho, la misma estatutaria : “... prohíbe expresamente la promoción u otorgamiento de cualquier tipo de dádivas o prebendas a profesionales de la salud en el marco de su ejercicio laboral, sean éstas en dinero o en especie por parte de proveedores, empresas farmacéuticas, productoras, distribuidoras o comercializadoras de medicamentos o de insumos, dispositivos y/o equipos médicos o similares".

Transparencia no es suficiente si no hay maestría, pericia, eficiencia y efectividad en la práctica médica. Nada es suficiente si falta el trato humano personalizado.

Hoy los enfermos son más demandantes. Con toda la razón exigen el goce efectivo de su derecho fundamental a la salud. También la autonomía es para ellos, pues es recíproca. La relación médico-paciente siempre debe estar signada por la confianza, pero para ello es necesario que la relación sea libre en la escogencia, con respeto recíproco, con información suficiente y con apego a los deberes de unos y otros. Hay derechos, pero también hay deberes.

La sociedad colombiana más que muchas otras, ha sido violentada en muchas esferas, lo que ha creado una percepción, una visión escéptica, una sensación de peligro, en todos los campos, y la salud no es la excepción.

Cuestionamos y nos quejamos de manera constante pero protestamos rara vez. Tenemos desconfianza en los médicos y en los enfermos, miramos con recelo a la industria con intereses en la salud, desconfiamos de empresas, de profesionales, de la ciencia y del gobierno.

Los cambios económicos de las últimas tres décadas han determinado cambios sociopolíticos con efectos en la cultura, transformando las relaciones entre médicos, enfermos, aseguradores, hospitales y gobierno. Desconfiamos todos de todos, pero paradójicamente le damos valor exagerado a las leyes, a las normas, y cuando nos enfermamos, tomamos los medicamentos que nos formulan aquellos médicos a los que acudimos en búsqueda de alivio. Esta realidad deja entrever que desconfiamos, pero queremos restablecer la confianza.

Acreditar y habilitar instituciones y personas, judicializar el acto médico, auditar procedimientos, son el quehacer de hoy con logros en cobertura, en número de actividades, pero con resultados pésimos en salud y en humanización.
La autonomía médica, y la autonomía de pacientes, como prerrequisitos para la construcción de confianza, deben concluir en calidad y humanización de la atención médica. La Ley Estatutaria de la Salud genera una oportunidad de oro para rehacer un modelo de atención orientado al pleno goce del derecho fundamental a la salud, desde el respeto por las autonomías.

La autorregulación, condición exigible para la autonomía médica, y la ética colectiva de la profesión médica (que no es otra cosa que la Lex artis), abren el camino conceptual para construir, entre todos, un modelo de atención en salud, que apunte a la calidad, medida con indicadores robustos de logros en salud, con transparencia y visibilidad del quehacer de los actores del sistema y con respeto absoluto a los intereses de los enfermos. Es necesario construir las bases materiales y sociales de la autonomía médica, para lo cual es indispensable un ejercicio profesional, cada vez más formalizado en servicios, con trabajo en equipo y con consideraciones altruistas. La remuneración justa y digna para los trabajadores de la salud, como lo ordena la ley estatutaria, es otra condición necesaria, amén de la garantía de su actualización y capacitación permanentes.

De acuerdo con la ley estatutaria:"los conflictos o discrepancias en diagnósticos y/o alternativas terapéuticas generadas a partir de la atención, serán dirimidos por las juntas médicas de los prestadores de servicios de salud, utilizando criterios de razonabilidad científica, de acuerdo con el procedimiento que determine la ley".

Teniendo en cuenta lo anterior, y en consideración a la prohibición expresa de constreñir el acto médico, y sabiendo que el código penal tipifica como delito tal conducta, podemos afirmar categóricamente que los llamados CTC, llegaron a su fin, pues no sólo atentan contra la autonomía médica, contradicen el mandato referente a la resolución de conflictos consagrado en el artículo 16 de la estatutaria, sino que en esencia es un acto de constreñimiento al profesional de la salud.

Hasta la fecha, las grandes reformas en salud han sido propiciadas por reformadores sociales, mientras los médicos ofician como espectadores. Hoy hemos sido los médicos, los autores de la columna vertebral de la reforma. Nuestra responsabilidad es de origen múltiple. Si con nuestro actuar diario no defendemos el regreso a la autonomía de nuestra profesión, si seguimos subordinados a aseguradores y patronos de hospitales y clínicas, si no exigimos el cumplimiento de la ley, sino devolvemos la dignidad de la profesión mediante un ejercicio ético, responsable, humanitario con los enfermos y con la sociedad, pasará mucho tiempo antes de que los médicos podamos ganarnos de nuevo el respeto de nuestros conciudadanos y habremos sido culpables de una nueva frustración de la sociedad. 